\title{
Using the WRF Regional Climate Model to Simulate Future Summertime Wind Speed Changes over the Arabian Peninsula
}

\author{
Hussain Alsarraf ${ }^{1 *}$ and Matthew Van Den Broeke ${ }^{2}$ \\ ${ }^{1}$ Kuwait Meteorology Department, Kuwait \\ ${ }^{2}$ Department of Earth and Atmospheric Sciences, University of Nebraska-Lincoln, USA
}

\begin{abstract}
The normal surface pressure distribution in the Middle East includes high pressure over the eastern Mediterranean Sea and low pressure over the southeastern Arabian Peninsula. The resulting west-east pressure gradient leads to summertime northerly or northwesterly shamal winds across the Arabian Peninsula, which typically result in many days per month with substantial lofted dust, leading to considerable human health and transportation impacts. It would be helpful to understand how the regional pressure gradient may change in the future, as the strength of this gradient exerts predominant control over the strength of the shamal wind. One factor possibly leading to changes in the strength of the pressure gradient is climate variability. We have simulated the regional climate under a presentday scenario (2006-2010) and a mid-century scenario (2056-2060) using the Weather Research and Forecasting (WRF) model. Our results indicate a weakening of the regional pressure gradient by mid-century, resulting in lower average wind speeds and fewer days conducive to dust storms across the Arabian Peninsula.
\end{abstract}

Keywords: Downscaling; Regional climate modeling; Sea-level pressure; Arabian peninsula; Shamal

\section{Introduction}

Variability of the Indian monsoon strongly affects the atmospheric circulation of the Middle East. Changes in sea-surface temperature (SST), soil moisture, sea ice, and Himalayan snow cover can lead to interannual variability of the Indian monsoon. It is important to understand the behavior of the Indian monsoon and its relationship with global climate during the summertime to be able to elaborate on how changes may affect regions influenced by the monsoon regime [1].

There is a link between global climate variability and Indian monsoon variability, and the forces that drive their variability can result from both external and internal forcings. One contributor to Indian summer monsoon precipitation variability is SST variability across the equatorial Pacific. For example, warm SST anomalies in the eastern equatorial Pacific and cool anomalies in the western equatorial Pacific result in the positive phase of the El Niño-Southern Oscillation (ENSO), which is one of the external forces that influence Indian monsoon precipitation [2]. The positive phase of ENSO weakens or reverses the Walker circulation across the equatorial Pacific, resulting in sinking air and decreased precipitation over Southeast Asia [3]. SSTs in the Indian Ocean can weaken or strength the subsidence, and cold SSTs over the Arabian Sea can lead to a decrease of monsoon precipitation [2]. Observations taken for longer periods of time suggest that Pacific Ocean SSTs are more strongly related to the Indian monsoon than Indian Ocean SSTs [2].

The Indian monsoon plays a key role in controlling the summer circulation over Asia and the Middle East. The reversal in the landocean temperature contrast during summertime drives the wind from the Arabian Sea toward the Indian subcontinent. Southeasterly wind over the southern Indian Ocean crosses the equator and is deflected due to the earth's rotation to become the southwesterly Somali Jet over the Arabian Sea to India. The onset of these winds coincides with the development of low pressure over India, resulting in a pressure gradient between the Indian subcontinent and Indian Ocean. This pressure gradient steers southerly flow into India to mature the summer monsoon, ultimately producing huge amounts of precipitation over India [1].
The Indian monsoon governs the northerly shamal wind in summertime over the Arabian Peninsula. The geographic location of the Zagros Mountains in western Iran forces a lee trough between the Persian Gulf and Iran. The pressure gradient across the Arabian Peninsula intensifies between this lee trough and high pressure over the Mediterranean Sea, which normally drives strong northerly (shamal) winds [4]. Intensification of the shamal wind in summer may cause frequent episodes of dust. Such dust storms can influence the earth's radiation budget, as the size and composition of dust aerosols can change the amount of shortwave radiation reaching the ground, affecting surface temperature [5]. A study by Francis et al. suggests that recent loss of sea ice may have consequences for atmospheric circulation on a hemispheric level. Sokolova et al. showed via a modeling study an association between low sea ice cover and the negative phase of the Arctic Oscillation (AO), indicating weaker zonal wind, although regional details are complicated by tracks of individual storm systems and atmospheric long-wave/low-frequency dynamic processes.

Observations indicate a reduction in the mean sea level pressure (MSLP) difference from east to west along the equatorial Pacific during the 20th century [6]. Observations of the pattern and strength of MSLP biases over the tropical Indo-Pacific from 1861-1992 concur with model-simulated changes when the model is forced with anthropogenic changes in radiative forcing [7].

Gillett et al. used four global climate models to investigate how these models explain observed changes in MSLP over the last 50 years. They found that that both polar regions have experienced MSLP decreases over the last 50 years, and that the North Atlantic Ocean,

${ }^{*}$ Corresponding author: Hussain Alsarraf, Kuwait Meteorology Department, Kuwait. Tel: +96599663313; E-mail: minnesotta@yahoo.com

Received November 23, 2015; Accepted December 10, 2015; Published December 17, 2015

Citation: Alsarraf H, Broeke MVD (2015) Using the WRF Regional Climate Mode to Simulate Future Summertime Wind Speed Changes over the Arabian Peninsula. J Climatol Weather Forecasting 3: 144. doi:10.4172/2332-2594.1000144

Copyright: ( 2015 Alsarraf $\mathrm{H}$, et al. This is an open-access article distributed under the terms of the Creative Commons Attribution License, which permits unrestricted use, distribution, and reproduction in any medium, provided the original author and source are credited. 
Europe, North Africa, India, and other tropical to mid-latitude regions have experienced a MSLP increase. Global climate models run both with and without the effects of greenhouse gases show a qualitatively similar pattern of global pressure redistribution. In the Arabian Peninsula, changes in the MSLP distribution would produce changes in wind speed, affecting magnitude and frequency of future dust storms.

In summertime, a thermal low is present over Pakistan and Afghanistan, extending west across southern Iran and the Persian Gulf (Figure 1). Along with the semi-permanent high pressure zone to the west, the resulting pressure gradient enhances southward airflow across the Arabian Peninsula similar to that described in Aurelius [4,8]. The intense pressure gradient may be enhanced by a dry cold frontal passage, allowing especially strong northerly and northwesterly winds.

Surface winds vary diurnally. Strong daytime solar heating causes intensification of low pressure over the southeastern Arabian Peninsula. The thermal low remains nearly stationary during the day, and weakens at night due to surface cooling. The daytime deepening of the thermal low leads to a steeper pressure gradient, causing surface wind speed to increase. Strong surface heating and friction leads to development of a deep well-mixed layer during the daytime. When such a well-mixed layer is created over dry regions, it tends to become relatively dry and characterized by a high lapse rate [9].

Any change in the strength of the high to the west or low to the east/ southeast may change the intensity of the pressure gradient, which may modify wind speed. Wind speed is a critical atmospheric variable for the Arabian Peninsula, since strong shamal winds in summertime may loft substantial quantities of dust with severe impacts on transportation and human health.

Changes in mean wind speed have been investigated globally and for different regions in the past, present, and future. Based on the results of Jiang et al. and observational data from the last 50 years, biases of the yearly and seasonal mean wind speeds over the globe have been calculated for the Northern Hemisphere. Decreasing trends in surface wind speed over land were found for middle and low latitudes, with increasing trends over high latitudes and some oceanic regions.

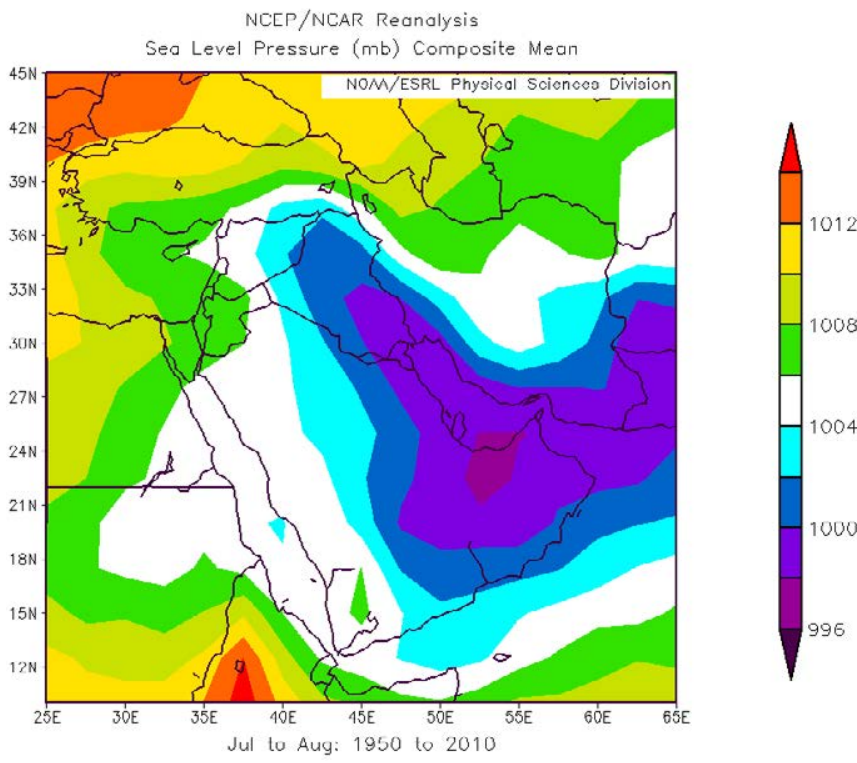

Figure 1: NCEP reanalysis data showing the climatological (1950-2010) summertime (June, July, August) MSLP (hPa) over the Arabian Peninsula.
Reductions in surface wind speed by $5 \%$ to $15 \%$ have been found in Central Asia, Eastern and Southern Asia, Europe, and North America in the last 30 years [10]. Several studies over the past 50 years in East Asia have found that the winter and summer meridional circulation indices in this region had experienced decreasing trends, whereas the zonal circulation indices had shown increasing trends. Vautard et al. associated the reduction of Northern Hemisphere wind speed with increased land-surface roughness. Another study by Bichet et al. [5] using simulated wind speed observations and anomalies averaged over 30 years indicates a wind speed decrease by $0.3 \%$ over the Northern Hemisphere. In this study, the Northern Hemisphere was divided into domains, where the Arabian Peninsula was located in the south Asia domain. The south Asian domain wind speed declined by $0.24 \%$. A decrease of wind speed globally and regionally in the Arabian Peninsula would decrease the potential for future dust storms.

Precipitation may also play a role in increasing or decreasing dust storm potential over the Arabian Peninsula. For instance, different precipitation characteristics of 1997, 2000, and 2008 were associated with differing numbers of days with summertime dust events in Kuwait. In past years, a slight increase in precipitation and decrease in wind speed has been observed in Kuwait. For the future, an increase of precipitation and decrease of wind speed been simulated over Kuwait by $\mathrm{Al}$-Zawad [11], indicating decreasing dust events in the future.

If future global warming reduces the temperature gradient between the poles and equator, mid-latitude winds should also be reduced. Such a reduction of the temperature gradient may change the location of the jet stream, which may modify tracks of mid-latitude cyclones. Recent evaluation of a past climate reanalysis determined that "jet streams have risen in altitude and moved poleward in both hemispheres" [12]. A poleward shift of the jet stream may result in fewer mid-latitude cyclones able to influence the Arabian Peninsula, leading to fewer days favorable for significant dust storms. Such a poleward shift in midlatitude cyclones has been noted in prior studies [13-16].

The mean summertime wind speed at Kuwait International Airport (KIA) decreased by $12 \%$ from 1973 to 2012 , averaging $32.4 \mathrm{~km} \mathrm{hr}^{-1}$ from 1973-1983 but only $28.5 \mathrm{~km} \mathrm{hr}^{-1}$ from 2002-2012. This decrease in wind speed may be driven partially by a decrease in the pressure gradient across the Arabian Peninsula, which may be partially attributable to global climate change. Given these observed changes, there is a need to investigate how wind speed, and therefore dust storm potential, may change regionally in the future under a warning climate scenario. We utilize a regional climate model to simulate the mid-century (20562060) summertime MSLP distribution across the Arabian Peninsula to answer the following questions:

(1) Will the pressure gradient weaken or strengthen across the Arabian Peninsula in the future?

(2) How will summertime mean surface wind speed be affected by changes to the MSLP distribution?

By determining whether wind speed may be expected to continue deceasing under a future climate scenario, for the first time we will be able to infer how dust storm potential may change by mid-century across the Arabian Peninsula.

\section{Experimental Design and Model Validation}

\section{WRF simulations and physics options}

Simulations in this study were completed using the Weather Research and Forecasting (WRF) model, version 3.3. The Advanced Research WRF (ARW) dynamic core was utilized, which is non- 
hydrostatic and fully compressible [17]. The Eta (Ferrier) microphysics scheme was specified-this is the microphysics scheme used in the North American Mesoscale (NAM) model, and has demonstrated validity in broad-scale simulations of mid-latitude precipitation microphysics. For shortwave radiation, the Dudhia simple downward calculation was selected [18], and for longwave radiation the Rapid Radiative Transfer Model (RRTM) scheme was used [19]. These radiation schemes are valid for cloudy or clear-sky conditions. Monin-Obukhov similarity theory was used for the surface layer, and for the land surface the Noah Land Surface Model was used by Ek [20], which includes information about the dominant vegetation and allows soil moisture to influence the overlying atmosphere. The Yonsei University scheme was used for the planetary boundary layer [21,22]. The Kain-Fritsch scheme was used for the cumulus parameterization [23]. More details on the physics options can be found in Table 1. WRF simulations were completed for a domain centered on the Arabian Peninsula for 1997, 2000 , and 2008, three years with different precipitation regimes across the region. Choosing three years with different climate history provides a more reliable test of the climate model output, and gives a better understanding of the model simulation under different climate regimes. WRF simulations with dynamic downscaling were forced by reanalysis using the National Centers for Environment Prediction (NCEP)/ National Center for Atmospheric Research (NCAR) Reanalysis Project output [24] for 1997, 2000, and 2008. These simulations are hereafter referred to as WRF-NCEP. Three WRF simulations were run: the first for a domain with 48-km horizontal resolution (D01), the second for a domain with $12-\mathrm{km}$ horizontal resolution (D02), and the third for a domain with 4-km horizontal resolution (D03).

\section{Model validation}

A preliminary verification was done to compare the output of the WRF simulations with observational data from Kuwait for the years 1997, 2000, and 2008. The variables that were compared with observational data include maximum temperature, MSLP, precipitation, and wind speed. These data were compared with observations in each downscaling nested domain.

In 1997, total precipitation at KIA $(215.3 \mathrm{~mm})$ was well above average. In 2000 , the precipitation $(80.27 \mathrm{~mm})$ was slightly lower than average, while in 2008 total precipitation $(50.9 \mathrm{~mm})$ was less than half the annual average. Number of dust days generally followed the precipitation, with 41 days recorded in 1997, 38 days in 2000, and 56 days in 2008. High annual precipitation in 1997 was associated with few dust storms, while very low precipitation in 2008 was associated with a high number of dust storms. Precipitation was low in 2000, but so was the number of dust storm days.

When more precipitation falls during winter, a higher wind speed is required to loft dust particles. In a normal precipitation year, an average wind speed of $35-40 \mathrm{~km} \mathrm{hr}^{-1}$ can cause blowing dust in summer, but in a high-precipitation year an average wind speed of at least $45 \mathrm{~km}$ $\mathrm{hr}^{-1}$ is required. The friction and surface roughness normally play a key role in identifying the speed of dust formation in the Arabian Peninsula and desert areas. As wind speed increases in the desert, the chance of dust events become greater and lower visibility is probable.

Downscaling results were first validated by comparing model output with observational data. Model output MSLP at $\left(29^{\circ} \mathrm{N}, 48^{\circ} \mathrm{E}\right)$ was compared with observations from KIA (also $29^{\circ} \mathrm{N}, 48^{\circ} \mathrm{E}$ ). A summary of the validation is presented in Table 2, which shows averages and standard deviations for June, July, and August of 1997, 2000, and 2008. The averages of the KIA observations and the WRF-NCEP $12 \mathrm{~km}$ and $4 \mathrm{~km}$ domains are very close, whereas the average of the $48 \mathrm{~km}$ output contains much higher pressure values. The root-mean-square error (RMSE) and the mean absolute error (MAE) calculations show the smallest magnitude of error at $4 \mathrm{~km}$ grid resolution (Table 2). A summary of the validation for wind speed in the 4-km WRF-NCEP run is shown in Table 3. The model tends to give slightly lower daily average wind speed values than the KIA observations, with similar standard deviation. Root-mean-square-error (RMSE) and mean-absolute-error (MAE) also indicate a relatively small magnitude of error at $4 \mathrm{~km}$ grid resolution (Table 3). Thus, we conclude that the results of D03 are the most representative, and show future wind speed results from D03 through the remainder of this paper.

\section{Model Results}

\section{GCM forcing}

In this part of the study, the Community Climate System Model

\begin{tabular}{|c|c|c|}
\hline Variable & Value & Description \\
\hline mp_physics & 4 & \\
\hline sst_update & 1 & allow sea surface temperature update \\
\hline ra_lw_physics & 1 & $\begin{array}{l}\text { (longwave radiation) RRTM scheme. Spectral scheme K-distribution Look-up table fit to accurate calculations. Interacts with clouds } \\
\text { Ozone/CO2 from climatology }\end{array}$ \\
\hline ra_sw_physics & 1 & $\begin{array}{l}\text { (short wave radiation) MM5 shortwave (Dudhia) Simple downward calculation. Clear-sky scattering. Water vapor absorption. Cloud } \\
\text { albedo and absorption }\end{array}$ \\
\hline radt & 20 & minutes between radiation physics calls \\
\hline sf_sfclay_physics & 1 & $\begin{array}{l}\text { (surface layer) Monin-Obukhov similarity theory. Taken from standard relations used in MM5 MRF PBL. Provides exchange coefficients to } \\
\text { surface (land) scheme. Should be used with bl_pbl_physics }=1 \text { or } 99 \text {. }\end{array}$ \\
\hline sf_surface_physics & 2 & $\begin{array}{l}\text { (land surface) Noah Land Surface Model: Unified NCEP/NCAR/AFWA scheme with soil temperature and moisture in four layers, fractional } \\
\text { snow cover and frozen soil physics }\end{array}$ \\
\hline bl_pbl_physics & 1 & $\begin{array}{l}\text { (Planetary Boundary layer) Yonsei University scheme: Non-local-K scheme with explicit entrainment layer and parabolic K profile in } \\
\text { unstable mixed layer. }\end{array}$ \\
\hline bldt & 0 & minutes between boundary-layer physics calls. $0=$ call every time step \\
\hline cu_physics & 1 & $\begin{array}{l}\text { (cumulus Parameterization) Kain-Fritsch scheme: Deep and shallow convection sub-grid scheme using a mass flux approach with } \\
\text { downdrafts and CAPE removal time scale }\end{array}$ \\
\hline cudt & 5 & minutes between cumulus physics calls \\
\hline icloud & 1 & cloud effect to the optical depth in radiation \\
\hline num_soil_layers & 4 & number of soil level or layer in WPS output \\
\hline
\end{tabular}

Table 1: Parameterizations used in WRF simulations for this study. 
Citation: Alsarraf H, Broeke MVD (2015) Using the WRF Regional Climate Model to Simulate Future Summertime Wind Speed Changes over the Arabian Peninsula. J Climatol Weather Forecasting 3: 144. doi:10.4172/2332-2594.1000144

Page 4 of 8

\begin{tabular}{|c|c|c|c|c|c|c|c|c|c|c|c|c|}
\hline \multirow{2}{*}{ MSLP } & \multicolumn{4}{|c|}{1997} & \multicolumn{4}{|c|}{2000} & \multicolumn{4}{|c|}{2008} \\
\hline & Obs & $4 \mathrm{~km}$ & $12 \mathrm{~km}$ & $48 \mathrm{~km}$ & Obs & $4 \mathrm{~km}$ & $12 \mathrm{~km}$ & $48 \mathrm{~km}$ & Obs & $4 \mathrm{~km}$ & $12 \mathrm{~km}$ & $48 \mathrm{~km}$ \\
\hline AVE & 994.9 & 999.4 & 998.8 & 1011.3 & 993.6 & 997.5 & 997.3 & 1009.9 & 993.6 & 997.5 & 995.8 & 1007.8 \\
\hline STDEV & 3.12 & 3.64 & 3.24 & 4.02 & 2.42 & 2.16 & 2.36 & 2.83 & 2.49 & 2.33 & 2.71 & 3.59 \\
\hline MAE & & 4.10 & 5.10 & 6.30 & & 3.81 & 4.13 & 6.27 & & 2.88 & 4.20 & 4.20 \\
\hline RMSE & & 4.67 & 5.66 & 6.68 & & 4.35 & 4.69 & 6.64 & & 3.51 & 4.85 & 4.69 \\
\hline
\end{tabular}

Table 2: Daily average summertime MSLP values (June, July, and August) simulated by WRF- NNRP for $48 \mathrm{~km}-, 12 \mathrm{~km}-, \mathrm{and}^{4} \mathrm{~km}-\mathrm{resolution}$ domains at $\left(29^{\circ} \mathrm{N}, 48^{\circ} \mathrm{E}\right)$ compared with Kuwait International Airport (KIA; $29^{\circ} \mathrm{N}, 48^{\circ} \mathrm{E}$ ) observations for 1997, 2000, and 2008. Standard deviation (STDEV), mean absolute error (MAE), and root mean square error (RMSE) are also shown for simulation results vs. observations.

\begin{tabular}{|c|c|c|c|c|c|c|}
\hline \multirow[t]{2}{*}{ Wind } & \multicolumn{2}{|c|}{1997} & \multicolumn{2}{|c|}{2000} & \multicolumn{2}{|c|}{2008} \\
\hline & Obs & $4 \mathrm{~km}$ & Obs & $4 \mathrm{~km}$ & Obs & $4 \mathrm{~km}$ \\
\hline AVE & 5.58 & 4.66 & 4.35 & 4.85 & 5.38 & 4.67 \\
\hline STDEV & 2.13 & 2.94 & 1.93 & 2.56 & 2.25 & 3.47 \\
\hline MAE & & 2.30 & & 2.30 & & 2.82 \\
\hline RMSE & & 2.89 & & 2.88 & & 3.45 \\
\hline
\end{tabular}

Table 3: Daily average summertime wind speed (June, July, and August) simulated by WRF- NNRP for 4-km resolution domain at (29 $\mathrm{N}$, $\left.48^{\circ} \mathrm{E}\right)$ compared with $\mathrm{KIA}$ observations $\left(29^{\circ} \mathrm{N}, 48^{\circ} \mathrm{E}\right)$ for 1997,2000 , and 2008 . Standard deviation (STDEV), mean absolute error (MAE), and root mean square error (RMSE) are also shown for simulation results vs. observations.

CCSM4 under the RCP8.5 scenario was used to provide lateral forcing for WRF runs for two five-year time periods, fifty years apart, to allow any climate change signal to be revealed. These runs are hereafter designated WRF-CCSM4. Two five-year periods were simulated: 20062010 (present-day climate) and 2056-2060 (mid-century climate). The second five-year period was chosen because going 50 years out helps assure the long-term signal will be clearly distinguished from shorterterm climate variability. The WRF runs were initialized at 0000 UTC on 27 April and ended on 3 October of each year, covering a total of 143 summer months (May-September). WRF model output was archived every three hours.

The left column of (Figure 2) shows the difference between the present-day (2006-2010) and mid-century (2056-2060) MSLP for May through September simulated by WRF-CCSM4. The right column of (Figure 2) shows the same MSLP difference simulated by WRF at $48-\mathrm{km}$ horizontal resolution (D01) forced by CCSM4. The CCSM4 simulates MSLP globally but does not sufficiently represent regional and local MSLP differences. The WRF runs, on the other hand, simulate effects that can change MSLP distributions on a synoptic or regional scale, such as coastlines.

\section{WRF model results}

Mean sea level pressure: The maps produced from WRFCCSM4 runs show the difference in average MSLP values from May to September (Figures 3-5) between the present (2006-2010) and mid-century (2056-2060). In May, MSLP increases over the Arabian Peninsula by up to $1.0 \mathrm{hPa}$, whereas west of the Arabian Peninsula it decreases up to $0.5 \mathrm{hPa}$ (Figure $3 \mathrm{a}$ ).

The month of June is normally dominated by a strong pressure gradient, and is characterized by strong shamal winds and dust storms. The gradient between low pressure to the southeast and the high pressure normally centered over the Mediterranean Sea is normally strong (Figure 1). The WRF-CCSM4 simulated differences in pressure for June indicate an increase in MSLP of 0.5 to $1.0 \mathrm{hPa}$ in the northern and central Arabian Peninsula, while in southern portions of the Arabian Peninsula an increase of 1.5 to $2.0 \mathrm{hPa}$ is indicated. In Iran, an increase of 1.5 to $2.0 \mathrm{hPa}$ is shown whereas pressure remains nearly the same or slightly decreases in the Mediterranean. An increase of up to $3.0 \mathrm{hPa}$ is indicated over the Himalayan Plateau, a large change between present and future climate conditions (Figure $3 \mathrm{~b}$ ).
July is also usually influenced by a strong pressure gradient across the Arabian Peninsula (Figure 1). The WRF-CCSM4 simulation results indicate an increase in MSLP of up to $1.0 \mathrm{hPa}$ across most of the Arabian Peninsula, with greater increases south of the Peninsula and to the northeast over Iran, where an increase of up to $3.0 \mathrm{hPa}$ is predicted. The western Arabian Peninsula is predicted to experience a MSLP decrease of approximately $0.5 \mathrm{hPa}$ (Figure 3c).

The WRF-CCSM4 results for August show a pressure decrease of up to $1.5 \mathrm{hPa}$ in the Arabian Peninsula. A decrease in MSLP of 1 to $2 \mathrm{hPa}$ throughout most of the northern part of the Middle East, the Mediterranean region, North Africa, and Western Europe is predicted, with a decrease of up to $2.5 \mathrm{hPa}$ in south Asia (Figure 3d). In September, the WRF-CCSM4 results indicate a pressure increase of up to $1.5 \mathrm{hPa}$ in the Arabian Peninsula, and an increase of up to $2 \mathrm{hPa}$ in Iran and India. North Africa and the Mediterranean Sea show a MSLP decrease from 1 to $2.5 \mathrm{hPa}$ (Figure 3e).

The downscaling $12 \mathrm{~km}$ horizontal resolution domain simulation (D02; Figure 4) indicates results similar to D01, with an increase in May of up to $1.0 \mathrm{hPa}$ over the Arabian Peninsula. In June, the WRF simulation shows an increase of 0.5 to $1.5 \mathrm{hPa}$ in the northern and central Arabian Peninsula, but the southern region near the Indian Ocean experiences an increase of 1.5 to $2.0 \mathrm{hPa}$. The Zagros Mountains in Iran show even more substantial pressure increases (Figure 4b). D02 in June shows that the thermal low and extension of the Indian monsoon is weakened, leading to a lessening of the pressure gradient across the region. In July, D02 indicates a MSLP increase by midcentury of up to $1.0 \mathrm{hPa}$ in the Arabian Peninsula (Figure 4c). In August, D02 shows similar results to D01, with a MSLP decrease by midcentury from 1 to $1.5 \mathrm{hPa}$ in the northeast Arabian Peninsula. Pressure in the central and southern Arabian Peninsula decreases by a lesser amount. The east Mediterranean Sea shows a pressure decrease up to $2.0 \mathrm{hPa}$, indicating that the region's semi-permanent high pressure area is weaker (Figure 4d). In September, D02 shows an increase in MSLP across the Arabian Peninsula, with a decrease over the Mediterranean Sea (Figure 4e).

The third downscaling domain (4 km grid resolution, D03; Figure 5) in May (Figure 5a) indicates a pressure increase of 0.5 to $1.0 \mathrm{hPa}$ in Kuwait, and from 0.5 to $1.5 \mathrm{hPa}$ in eastern Saudi Arabia, Qatar, and the United Arab Emirates. In June (Figure 5b), pressure increases from 1.0 to $2.0 \mathrm{hPa}$ across much of the same region. In July (Figure $5 \mathrm{c}$ ), pressure 
Citation: Alsarraf H, Broeke MVD (2015) Using the WRF Regional Climate Model to Simulate Future Summertime Wind Speed Changes over the Arabian Peninsula. J Climatol Weather Forecasting 3: 144. doi:10.4172/2332-2594.1000144

Page 5 of 8

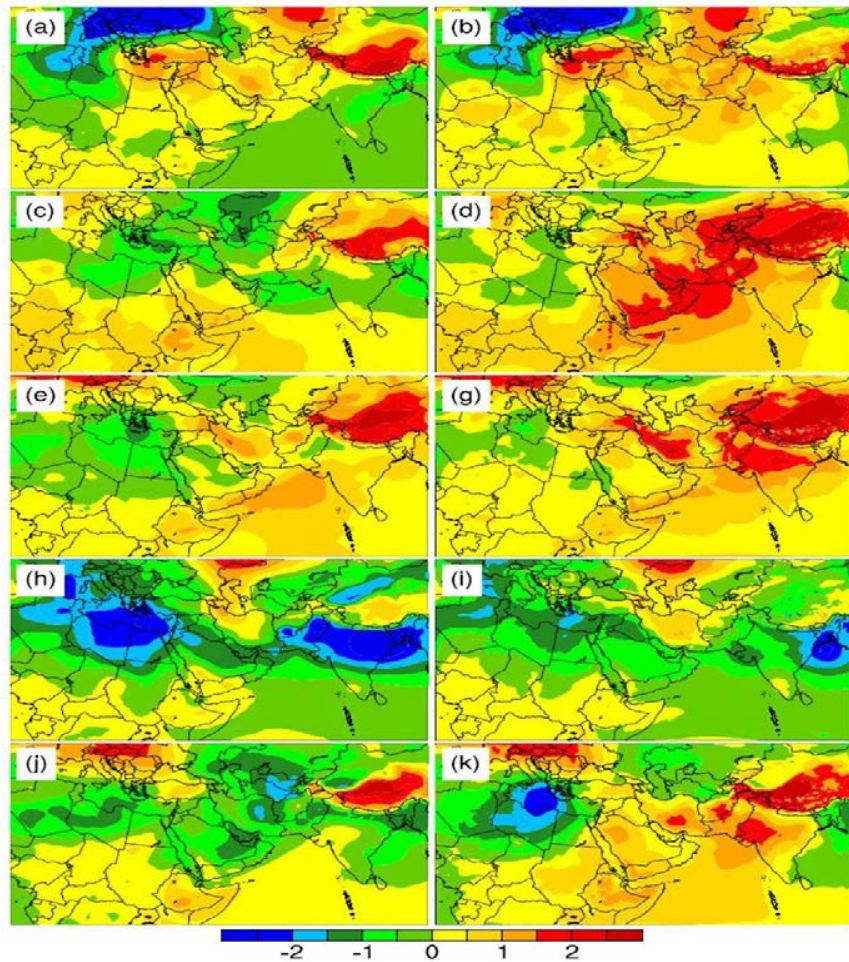

Figure 2: Left column: MSLP difference between present (2006-2010) and mid-century (2056-2060) CCSM4 global climate model simulations for (a) May, (c) June, (e) July, (h) August, and (j) September. Right column: same except for WRF (48 km grid spacing) forced by CCSM4 for (b) May, (d) June, (g) July, (i) August, and (k) September.

increases across most of the same region, but less than in June. In August D03 shows a pressure decrease from 1.0 to $2.0 \mathrm{hPa}$ region-wide (Figure 5d). By September, D03 indicates a pressure increase from 1.5 to $2.0 \mathrm{hPa}$ over most of the region (Figure $5 \mathrm{e}$ ). The three simulations, while qualitatively similar, yield slightly different quantitative results since grid resolution varied. Given that results from the finer-resolution domain (D03) most closely matched observations at KIA (Table 2), this simulation likely provides the best illustration of how the pressure field may vary across the Arabian Peninsula in the future.

The main motivation for simulating the MSLP using WRF is to examine the future changes in pressure gradients. The three downscaling simulations tend to provide similar results in terms of the changes in MSLP strength, and the indication of the weakening of the pressure gradient that develops in summertime in the Arabian Peninsula. The circulation patterns in summertime are controlled by the summer Indian monsoon leading to northerly winds in summer; the steeper the pressure gradient the stronger the northerly to northwesterly wind. The thermal low that develops in the southeastern Arabian Peninsula steepens the pressure gradient over the Arabian Peninsula as was seen in the case study. The WRF simulations for summertime show that the southeastern region where the thermal low normally develops over southeastern Saudi Arabia, United Arab Emirates (UAE), or northeast Oman will weaken in the future. The weakening of this feature will lead to a flattening of the regional pressure gradient. The WRF simulations for MSLP indicate a weakening pressure gradient, which results in fewer days with moderate to strong northerly to northwesterly wind in summertime. In late August, the pressure gradient begins to weaken, leading to the development of a more mesoscale circulation over the
Arabian Peninsula, and the region becomes more favorable to the development of thermal lows. The WRF simulations shows a decrease of MSLP in the Arabian Peninsula in August, which indicates that there will be a shorter period of strong pressure gradients that will

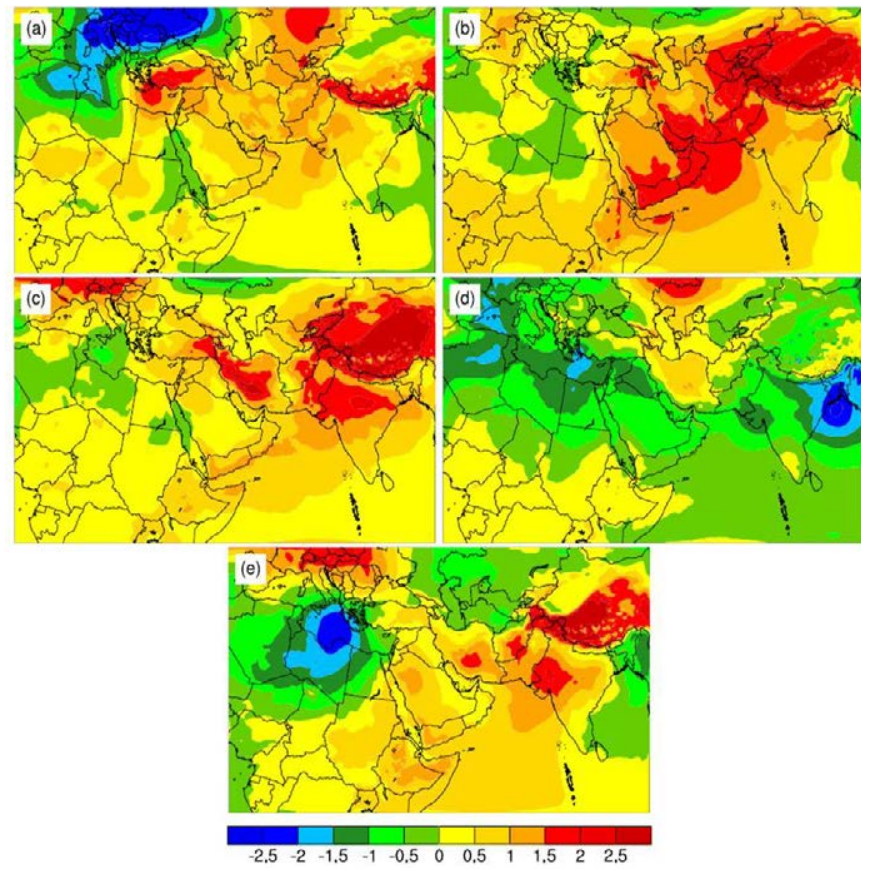

Figure 3: As in the right column of Figure 2, except WRF-CCSM4 simulations (48-km horizontal resolution; D01) for (a) May, (b) June, (c) July, (d) August, and $(e)$ September.
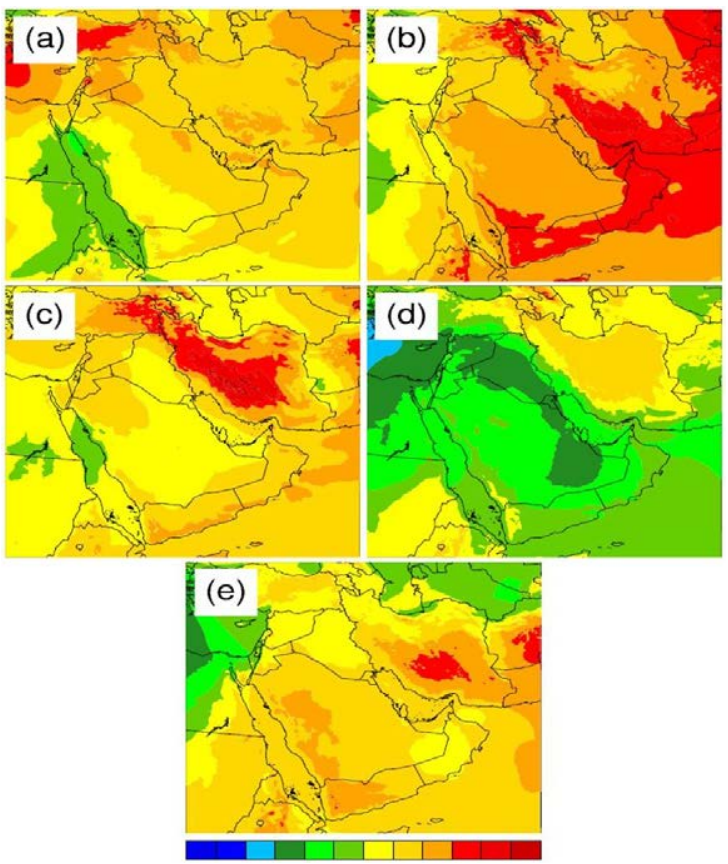

Figure 4: As in Figure 3,except WRF-CCSM4 simulations with 12-km horizontal resolution (002) for (a) May, (b) June, (c) July, (d) August, and (e) September 


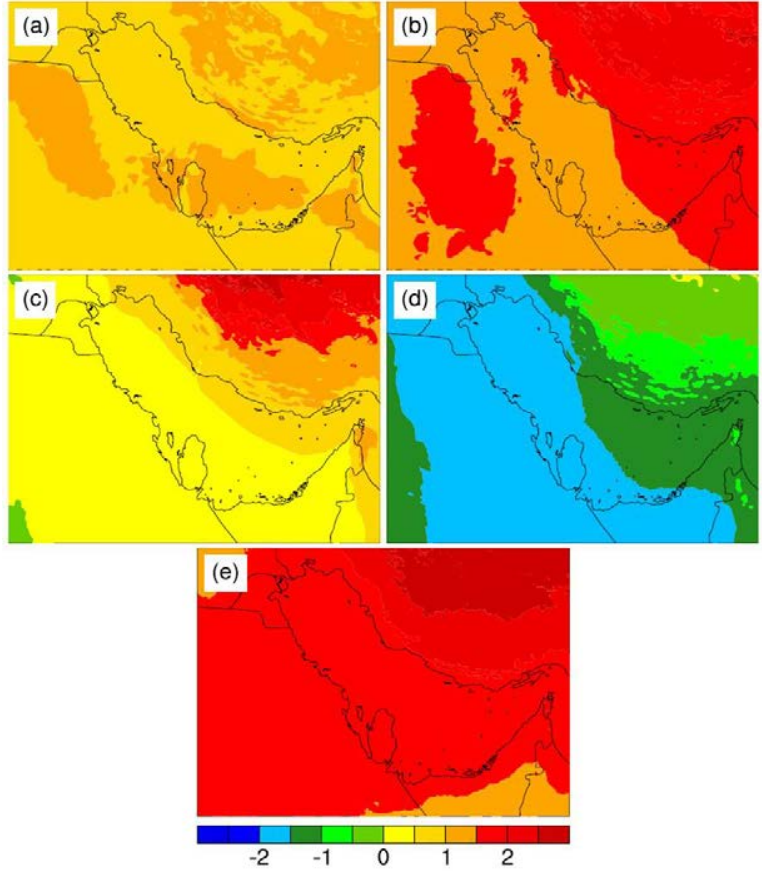

Figure 5: As in Figure 3, except WRF-CCSM4 simulations with 4-km horizontal resolution (D03) for (a) May, (b) June, (c) July, (d) August, and (e) September.

weaken very early in August. The weak synoptic forcing will lead to humid air advecting inland from the Persian Gulf into the peninsula, and more days with light to moderate easterly and southeasterly winds rather than strong shamal. This indicates that in the future, August will experience fewer dust storms and more humid days, and an increase in number of days with a mesoscale circulation such as a land/sea breeze in June, July, and August.

Wind speed: For the 4-km domain (D03), difference in wind speed between the present and mid-century was also plotted (Figure 6). During May (Figure 6a), a slight increase in wind speed (up to $1 \mathrm{~m}$ $\mathrm{s}^{-1}$ ) is indicated over Kuwait, eastern Saudi Arabia, Bahrain, southern Qatar, and the UAE, with a slight decrease in wind speed (up to $1 \mathrm{~m}$ $\mathrm{s}^{-1}$ ) along the south shore of Kuwait, eastern shore of Saudi Arabia, and northern Qatar. In June, mid-century wind speed is slightly decreased over most land areas of the Arabian Peninsula (Figure 6b), with slight increases over Qatar and southern Saudi Arabia. In July, wind speed is predicted to decrease slightly across much of the Arabian Peninsula, and up to $2 \mathrm{~m} \mathrm{~s}^{-1}$ across portions of Kuwait, Iraq, and Iran (Figure 6c). By August (Figure 6d), wind speed is predicted to decrease over the Persian Gulf, eastern Kuwait, eastern Saudi Arabia, Bahrain, Qatar, and UAE, with an increase of wind speed farther west. In September (Figure 6e), wind speed is predicted to decrease slightly in the northern Arabian Peninsula and increase slightly in the southeastern Arabian Peninsula. These results are summarized in Table 4.

Daily average wind speed in Kuwait: The daily mean of surface wind speed $\left(\mathrm{m} \mathrm{s}^{-1}\right)$ for the high-resolution domain (D03) of the WRFCCSM4 was computed. The motivation is to compare the daily average wind speed between present and future in Kuwait, and to examine if there may be days in the future with stronger daily average wind speeds.

The results of the WRF-RCM daily mean wind speed prediction was arranged from highest to lowest values in the present (2006 to 2010). These five years were then averaged to produce a graph of daily averaged wind speed arranged from higher to lower values. A similar calculation was performed for the future (2056-2060) to compare the slopes of both graphs. The graph in Figure 7 represents daily wind speed in red for the present and blue for the future. The graph implies that there are more days with a higher daily mean wind speed for the present compared to the future. The result indicates that in the future (2056-2060) fewer days will be experienced with strong winds compared to the present in Kuwait. This conclusion is supported by the results of a Wilcoxon-Mann- Whitney test. When the two populations of daily mean wind speed (2006-2010 and 2056-2060) are compared, $\mathrm{p}=0.0209$, indicating a high likelihood that the two mean wind speed populations are indeed different, e.g., the mean wind speed will likely become lower under a future climate scenario.

Threshold wind speed for dust days: Thirty years of observational data from Kuwait International Airport was used to determine a threshold for dust events (blowing dust, dust storms, and sand storms) from an average daily $10-\mathrm{m}$ wind speed. We investigated values of daily average wind speed of $\geq 4.5 \mathrm{~m} \mathrm{~s}^{-1}, \geq 5.0 \mathrm{~m} \mathrm{~s}^{-1}, \geq 5.5 \mathrm{~m} \mathrm{~s}^{-1}$, and $\geq 6.0 \mathrm{~m}$ $\mathrm{s}^{-1}$ to determine the optimal mean daily wind speed threshold for dust days in Kuwait. A percentage of $88.8 \%$ dust days were found for a mean daily wind speed threshold of $\geq 5.0 \mathrm{~m} \mathrm{~s}^{-1}$.

\section{Discussion}

The main motivation for simulating MSLP using WRF-CCSM4 is to examine future changes in the pressure gradient and wind speed across the Arabian Peninsula, which allows an inference about possible future regional dust storm frequency changes. The three downscaling simulations for MSLP produce qualitatively similar results, and indicate weakening of the summertime pressure gradient across the Arabian Peninsula. The regional circulation pattern in summer is controlled by the summer Indian monsoon, with a steeper pressure gradient

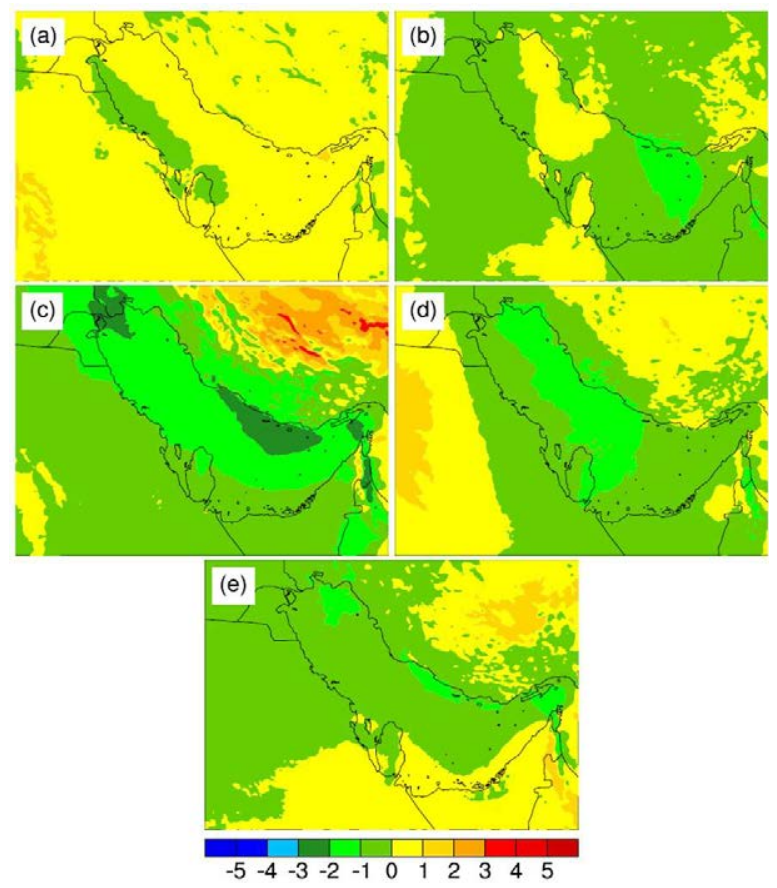

Figure 6: As in Figure 5, except wind speed difference $\left(\mathrm{m} \mathrm{s}^{-1}\right)$ between present (2006-2010) and mid- century (2056-2060) for (a) May, (b) June, (c) July, (d) August, and (e) September. 


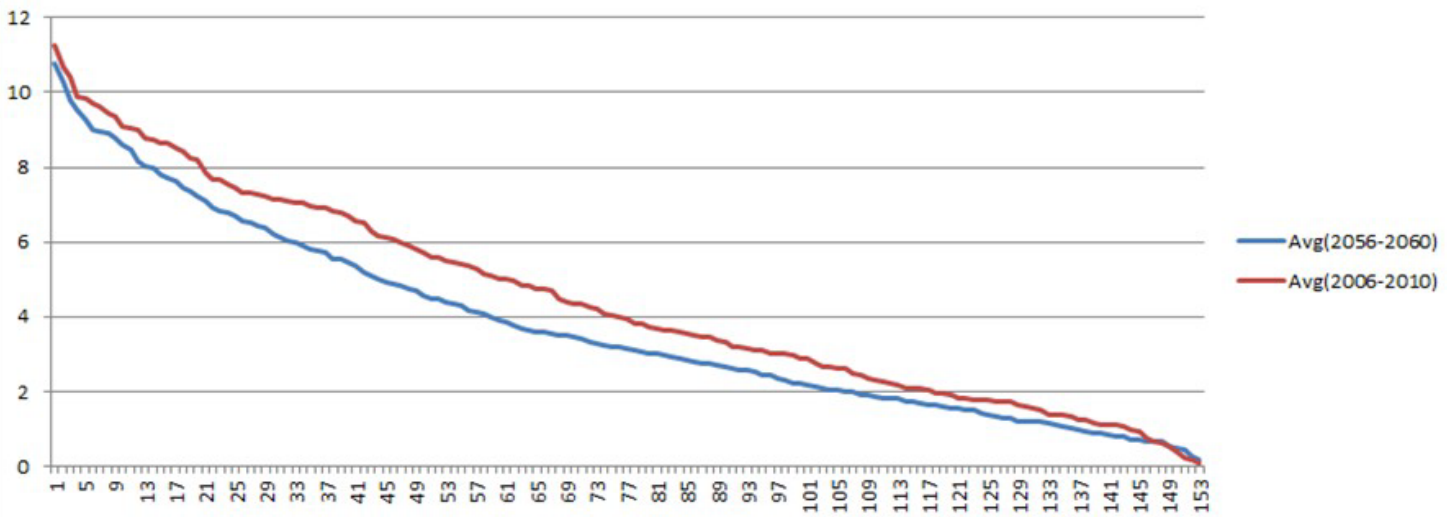

Figure 7: Ranked daily average wind speed for present (2006-2010) averaging the five years in red, and the ranked daily average wind speed for the future (20562060) averaging the five years in blue. Individual years are ranked separately prior to averaging over the 5-year simulation.

wind speed 1973-2012

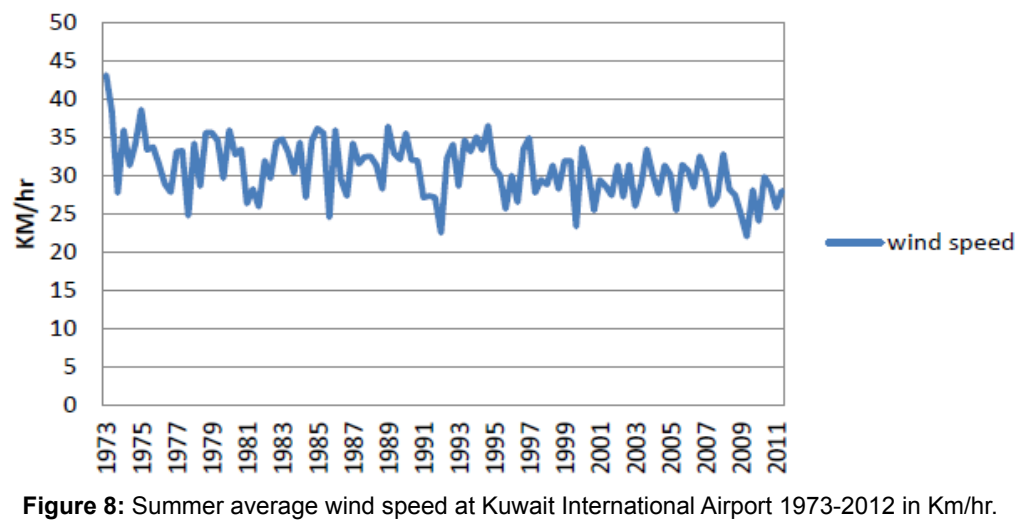

leading to stronger northerly to northwesterly wind. Prior studies have indicated little change in intensity of the Indian monsoon circulation by the end of the 21st century [25]. A thermal low that develops in the southeastern Arabian Peninsula steepens the pressure gradient in this region (Figure 1). WRF-CCSM4 simulations for summertime show that this thermal low may weaken in the future, leading to a flattening of the pressure gradient. In addition, the high pressure area over the Mediterranean Sea is also anticipated to weaken. A weakening pressure gradient would result, allowing fewer summertime days with moderate to strong northerly to northwesterly wind. By late August the strong pressure gradient begins to weaken, making the region more conducive to the development of thermal lows. The WRF-CCSM4 simulations show a MSLP decrease in the Arabian Peninsula during August, which indicates that there may be a shorter period dominated by a strong pressure gradient, which will weaken very early in August. The weakened synoptic forcing will lead to moisture advection inland from the Arabian Gulf into the Arabian Peninsula, and more days with light to moderate easterly and southeasterly winds rather than strong shamal. The WRF-CCSM4 simulations of future wind speed indicates a decreasing wind speed in the eastern portion of the Arabian Peninsula in June, July, August, and September. This indicates that, in the future, the region will experience a decrease in the number of summertime days with strong pressure gradients and dust storms, and an increase in the number of days with mesoscale circulations such as the land-sea breeze. Confidence in this result is strengthened by a Wilcoxon-Mann-
Whitney test, which indicated $\sim 98 \%$ certainty that the mean wind speed distributions are different between the present and mid-century.

WRF dynamical downscaling runs were investigated for three domains to investigate if there will more or fewer days with winds exceeding a mean daily $10-\mathrm{m}$ threshold of $5.0 \mathrm{~m} \mathrm{~s}^{-1}$ in the future, comparing the present (2006-2010) with the future (2056-2060). The results of D03 indicate 40.8 days on average of daily mean wind speed thresholds $\geq 5.0 \mathrm{~m} \mathrm{~s}^{-1}$ in the present-day, with the results for mid-century showing 27 days. These results indicate less future days with a wind speed exceeding the threshold for dust, consistent with the finding of a lower mean future wind speed. The KIA summer mean wind speed observation from 1973-2012 indicates a declining summertime wind speed (Figure 8).These observation from the past 40 years show a similar trend to what the D03 high resolution model predicts in the future.

These results provide further support for prior research which indicates decreasing future wind speed over southern Europe [11,26,27]. Decreasing future wind speed is consistent with a continuation of the trend of decreasing wind speed over land globally and in the Arabian Peninsula as observed over recent decades [5]. The reduction in future wind speed seen in our simulations occurred without accounting for any vegetation changes, which may also be locally important through roughness length considerations [27]. Changing precipitation distributions through the year, leading to 
Citation: Alsarraf H, Broeke MVD (2015) Using the WRF Regional Climate Model to Simulate Future Summertime Wind Speed Changes over the Arabian Peninsula. J Climatol Weather Forecasting 3: 144. doi:10.4172/2332-2594.1000144

changes in soil moisture and the ability of dust to be lofted, should be investigated in more detail. Such changes are closely tied to the mean tracks of mid-latitude cyclones, which may shift poleward [12]. If less mid-latitude weather disturbances influence the Arabian Peninsula, precipitation may decline and wind speed may decrease, which have opposite implications for the number of dust storm-favorable days in the region.

\section{Conclusion}

The WRF-CCSM4 results show similar MSLP patterns between the present and mid-century, but they indicate a change in the magnitude of the surface pressure. The WRF-CCSM4 indicates an increase in pressure east of the Arabian Peninsula where low pressure forms in the summer. This low pressure normally forms east of the region due to the Indian monsoon or the thermal low pressure created due to solar heating. The summertime Mediterranean high pressure area is expected to experience a future decrease in intensity. The Mediterranean high pressure west of the Arabian Peninsula and the low pressure east of the region usually result in northerly to northeasterly flow across the region. The southeast thermal low that develops usually steepens the pressure gradient across the Arabian Peninsula. This gradient will subsequently weaken by mid-century, resulting in decreasing summertime wind speed and a possible reduction in the number of days favorable for dust events. This change will alter the amount of the aerosol in the atmosphere and will cause regional changes in absorption and scattering of long wave and shortwave radiation. Potential next steps in this research area include using high-resolution WRF climate modeling to examine such changes in summertime environmental physics over the region by mid-century.

\section{References}

1. Boos WR, Emanuel KA (2009) Annual intensification of the Somali jet in a quasi-equilibrium framework: Observational composites. Quarterly Journal of the Royal Meteorological Society 135: 319-335.

2. Ihara C, Kushnir Y, Cane MA (2008) July droughts over Homogeneous Indian monsoon region and Indian Ocean dipole during El Niño events. International Journal of Climatology 28: 1799-1805.

3. Fischer AS, Terray P, Guilyardi E, Gualdi S, Delecluse P (2005) Two independent triggers for the Indian Ocean Dipole/zonal mode in a coupled GCM. Journal of Climate 18: 3428-3449.

4. AISarraf H, Van Den Broeke M (2015) Using high-resolution WRF model simulations to investigate the relationship between mesoscale circulations and aerosol transport over Kuwait. Journal of Climatology and Weather Forecasting 3: 3-126.

5. Bichet A, Wild M, Folini D, Schär C (2012) Causes for decadal variations of wind speed over land: Sensitivity. Geophysical Research Letters 39: 11701.

6. Karnauskas KB, Seager R, Kaplan A, Kushnir Y, Cane MA (2009) Observed strengthening of the zonal sea surface temperature gradient across the equatorial Pacific Ocean. J. Climate 22: 4316-4321.

7. DiNezio PN, Vecchi GA, Clement AC (2013) Detectability of changes in the Walker Circulation in response to global warming. J. Climate 26: 4038-4048.

8. Aurelius L, Buttgereit V, Cammelli S, Zanina M (2008) The impact of Shamal winds on tall building design in the Gulf. Dubai Building Government of Dubai.
9. Salmond JA, McKendry IC (2005) A review of turbulence in the very stable nocturnal boundary layer and its implications for air quality. Progress In Physical Geography 29: 171-188.

10. Zhao Z, Luo $Y$, Jiang $Y$ (2011) Is global strong wind declining? Adv. Climate Change Res 2:225-228.

11. Al-Zahrani M (2008) Impacts of climate change on water resources in Saudi Arabia. Arabian Journal for Science and Engineering 38: 1959-1971.

12. Koch P, Weirnli H, Davies HC (2006) An event-based jet-stream climatology and typology. Int. J. Climatology 26: 283-301.

13. Bengtsson L, Hodges K. Froude L (2005) Global observations and forecast skill. Tellus A Dynamic Meteorology and Oceanography 57: 515-527.

14. Solomon S, Qin D, Manning M, Chen Z, Marquis M, et.al, (2007) The Physical Science Basis. Contribution of Working Group I to the Fourth Assessment Report of the IPCC. Cambridge University Press, Cambridge, United Kingdom and New York, USA.

15. Mesquita MDS, Nils GK, Asgeir S, David EA (2008) Climatological properties of summertime extra-tropical storm tracks in the Northern Hemisphere. Tellus 60: 557-569.

16. Chu C, Yang X, Ren X, Zhou T (2013) Response of Northern Hemispheric storm tracks to Indian-western Pacific Ocean warming in atmospheric genera circulation models. Climate Dynamics 40: 1057-1070.

17. Skamarock W, Klemp J, Dudhia J, Gill D, Barker D, et.al, (2008) A description of the Advanced Research WRF version 3. NCAR Tech. Note NCAR/TN 4751STR 113

18. Dudhia J (1989) Numerical study of convection observed during the Winter Monsoon Experiment using a mesoscale two-dimensional model. J. Atmos. Sci 46: 3077-3107.

19. Mlawer EJ, Taubman SJ, Brown PD, lacono MJ, Clough SA (1997) Radiative transfer for inhomogeneous atmospheres: RRTM, a validated correlated- $k$ model for the longwave. J. Geophys. Res. Atmos 102: 16663-16682.

20. Ek MB, Mitchell KE, Lin Y, Rogers E, Grunmann P, et.al, (2003) Implementation of Noah land surface model advances in the National Centers for Environmental Prediction operational mesoscale Eta model. J. Geophys. Res. Atmos 108.

21. Hong S, Noh Y, Dudhia J (2006) A new vertical diffusion package with an explicit treatment of entrainment processes. Mon. Weather Review 134: 23182341.

22. Hong SY (2010) A new stable boundary-layer mixing scheme and its impact on the simulated East Asian summer monsoon. Quart. J. Roy. Meteor. Soc 136: $1481-1496$.

23. Kain JS (2004) The Kain-Fritsch convective parameterization: An update. J. Appl. Meteor 43: 170-181.

24. Kistler R, William C, Suranjana S, Glenn W (2001) The NCEP-NCAR 50-year reanalysis: Monthly means CD-ROM and documentation. Bull. Amer. Meteo Soc 82: 247-267.

25. Kumar KK, Kamala K, Rajagopalan B, Hoerling MP, Eischeid JK, et.al, (2011) The once and future pulse of Indian monsoonal climate. Climate Dynamics 36: $2159-2170$.

26. Jiang Y, Luo Y, Zhao Z (2009) Review of research on wind resources changes in China and in the world. Review on Science \& Technology 27: 96-104.

27. Tobin I, Vautard R, Balog I, Bréon F, Jerez S, et al. (2015) Assessing climate change impacts on European wind energy from ENSEMBLES high-resolution climate projections. Climatic Change 128: 99-112. 